\title{
Use of Virtual Reality Therapy (VRT) for Vestibular Rehabilitation
}

\author{
Sierra Hunnicut and Lilian Felipe* \\ Department of Speech and Hearing Sciences, Lamar University, Beaumont, Texas, USA \\ *Corresponding author: Lilian Felipe, Department of Speech and Hearing Sciences, Beaumont, Texas, USA
}

\begin{tabular}{|c|c|}
\hline ARTICLE INFO & ABSTRACT \\
\hline Received: 㓞 October 17, 2019 & Citation: Sierra Hunnicut, Lilian Felipe. Use of Virtual Reality Therapy (VRT) for \\
\hline Published: 幽 October 30, 2019 & Vestibular Rehabilitation. Biomed J Sci \& Tech Res 22(3)-2019. BJSTR. MS.ID.003740. \\
\hline
\end{tabular}

\section{Introduction}

Corporal balance is composed by the vestibular, visual and proprioceptive systems [1]. The vestibular system acts as a gravity sensor controlling the dynamic posture. Vestibular dysfunctions may be peripheral and/or central, occurring by primary or secondary causes, having as main manifestations, body sway under visual or somatosensory conflict conditions, reduced stability and functional capacity, gait deviations and falls [2]. Dizziness is one of the most common complaints to physicians worldwide, and in United States it is responsible for over 8 million health appointments per year [3]. Around 40 to 50 percent of people over the 40's has experienced dizziness or imbalance [1]. Vestibular disorders are a range in disorders in which an individual is imbalanced [4]. Patients with vestibular disorders experience dizzy triggers, and due to this factor, an increasing of risk for falling and/or getting injured [5]. Vestibular disorders have several alternatives of treatment, and one of them is the vestibular rehabilitation. The vestibular rehabilitation combines physical movements with exposure to different sensory inputs to reduce symptoms and improve balance problems. The vestibular rehabilitation is a treatment that associate physical movements with exposure to diverse sensory inputs to decrease symptoms and enhance balance. Part of the intervention is to execute exercises that incorporate visual-vestibular and/or somatosensory-vestibular conflict $[2,5,6]$. Vestibular rehabilitation is founded on mechanisms associated to the neuronal plasticity of the central nervous system, known as adaptation, habituation and substitution, where nerve cells create new synaptic connections growing its neural arrangement [2]. Virtual Reality (VR) is computer technology aimed to replicate or modify a user's physical presence in an illusory, yet representative, setting. It has been used for didactic and amusement reasons, as well as immersive video games. It has now created its way into the dominion of healthcare and remains to make progresses in how experts and specialists can assistance develop their patients' outcomes [7].

\section{Objective}

To verify the application of virtual reality in the vestibular rehabilitation process.

\section{Discussion}

In Virtual Reality Therapy (VRT) it is possible to replicate, using an appropriate software, real spaces in a multisensory setting through resources that can intensify sensations such as special helmets, belts, headphones, platforms and use of environment displays. This allows the user to interact and emerge in a virtual world in real time through multi sensations, facing them and getting involved and motivated to perform the proposal activity [8]. This technology offers an extensive variety of specific stimuli and sensory conflicts of different degrees of complexity in a safe environment [9]. Studies has shown the use of VR in clinical management through diverse healthcare areas as efficient in treatments, including developing gait in physical therapy, treating post-traumatic stress disorder and phobia controlling [9-12]. For vestibular disorders treatment, the VR is considered a new instrument for treatment with favorable results. Virtual reality improves a patient's condition through balance training. This tool can improve motor skills and postural control abilities in order to prevent risk of falling [1222]. The VRT has contributed to enhancement of postural balance, motor coordination mobility, flexibility, physical function, also improved of stability limit; decreasing dizziness levels and rates of falls, offering functional independence and quality of life for the patients [13-23]. 
This technology applied in vestibular rehabilitation can offer numerous positive aspects not just in successfully recover balance patient's abilities, providing superior results to assistance and improve postural control and supporting the improvement of motor learning. The significance of using VR as a therapeutic technique is interconnected to the capability to provide a range of stimuli if compared to conventional vestibular rehabilitation; allowing the patient sensory divergences at distinctive levels of difficulty and in a safe environment that will stimulate enhancement balance and posture, improve mobility, the functionality of upper and lower limbs, additionally encouraging and motivating the patient during therapy [10-22]. Another benefit is the ability to custom the VR system to for the vestibular rehabilitation in the comfort of the patient own home. They would be able to complete rehabilitation inside their house, with the assistance of the clinician or family member, creating motivation to continue the therapy [14]. Several studies have been published, which, however, requisite further investigations, requesting stricter protocols [6,10-23]. With improvements in technology, VR based companies are trying to minimize the cost of the devices and software used to make rehabilitation programs more affordable and accessible to the public [13]

\section{Conclusion}

The visual, vestibular, and proprioceptive divergences produced by virtual reality stimulation technology can offer an extensive array of sensory stimuli to generate conflicts of variable degrees of difficulty in a secure setting. Therapy in virtual reality proposes a relationship between the individual and the machine, suggesting that it is in another reality in which the perception of the environment is altered by sensory stimuli. Additional studies on the use of rehabilitation supported by virtual reality in vestibular disorders are necessary to corroborate how successfully the body balance functional tests can be used in the short and long terms.

\section{References}

1. Pankanin ES (2018) The impact of hearing disorders on the body balance. Journal of Education, Health and Sport 8(7): 244-249.

2. Arnold SA, Stewart AM, Moor HM, Karl RC, Reneker JC (2017) The Effectiveness of Vestibular Rehabilitation Interventions in Treating Unilateral Peripheral Vestibular Disorders: A Systematic Review. Physiother Res Int 22(3).

3. Sulway S, Whitney SL (2019) Advances in Vestibular Rehabilitation. Adv Otorhinolaryngoly 82: 164-169.

4. Cousins S, Cutfield NJ, Kaski D, Palla A, Seemungal BM (2013) Visual dependency and dizziness after vestibular neuritis. PLoS One 9(9): e105426.

5. Whitney SL, Alghadir A, Alghwiri A, Alshebber KM, Alshehri M (2016) The development of the ICF vestibular environmental scale. Journal of Vestibular Research: Equilibrium \& Orientation 26(3): 297-302.

6. Lange B, Flynn S, Proffitt R, Chang CY, Rizzo AS (2010) Development of an interactive game-based rehabilitation tool for dynamic balance training. Topics in Stroke Rehabilitation 17(5): 345-352.
7. Robertson I (1990) Does computerized cognitive rehabilitation work? A review. Aphasiology 4(4): 381-405.

8. Costa RT da, Carvalho MRM de, Ribeiro P, Nardi AE (2018) Virtual reality exposure therapy for fear of driving: analysis of clinical characteristics, physiological response, and sense of presence. Revista Brasileira De Psiquiatria 40(2): 192-199.

9. Rothbaum BO, Hodges LF (1999) The use of virtual reality exposure in the treatment of anxiety disorders. Behavior Modification 23(4): 507 525.

10. Song JJ (2019) Virtual Reality for Vestibular Rehabilitation. Clin Exp Otorhinolaryngol 12(4): 329-330.

11. Ju Hong K (2018) Effects of a virtual reality video game exercise program on upper extremity function and daily living activities in stroke patients. Journal of Physical Therapy Science 30(12): 1408-1411.

12. Prasertsakul T, Kaimuk P, Chinjenpradit W, Limroongreungrat W, Charoensuk W (2018) The effect of virtual reality-based balance training on motor learning and postural control in healthy adults: a randomized preliminary study. Biomedical Engineering Online 17(1): 124.

13. Alahmari KA, Sparto PJ, Marchetti GF, Redfern MS, Furman JM (2014) Comparison of Virtual Reality Based Therapy with Customized Vestibular Physical Therapy for the Treatment of Vestibular Disorders. IEEE Trans. Neural Syst. Rehabil. Eng 22(2): 389-399.

14. Meldrum D, Herdman S, Moloney R, Murray D, Duffy D, et al. (2012) Effectiveness of conventional versus virtual reality based vestibular rehabilitation in the treatment of dizziness, gait and balance impairment in adults with unilateral peripheral vestibular loss: a randomized controlled trial. BMC Ear, Nose \& Throat Disorders 96(7): 1319-1328.

15. Nehrujee A, Vasanthan L, Lepcha A, Balasubramanian S (2019) A Smartphone-based gaming system for vestibular rehabilitation: A usability study. J Vestib Res 29(2-3): 147-160.

16. Micarelli A, Viziano A, Alessandrini M (2019) Role of head-mounted displays in enhancing vestibular rehabilitation effects: Comment on Evaluation of the effectiveness of a Virtual Reality-based exercise program for Unilateral Peripheral Vestibular Deficit. J Vestib Res.

17. Zaleski King A, Pinto R, Lee G, Brungart D (2019) Use of Commercial Virtual Reality Technology to Assess Verticality Perception in Static and Dynamic Visual Backgrounds. Ear Hear.

18. Park JH, Jeon HJ, Lim EC, Koo JW, Lee HJ, et al. (2019) Feasibility of Eye Tracking Assisted Vestibular Rehabilitation Strategy Using Immersive Virtual Reality. Clin Exp Otorhinolaryngol 12(4): 376-384.

19. Lubetzky AV, Hujsak BD (2018) A virtual reality head stability test for patients with vestibular dysfunction. J Vestib Res 28(5-6): 393-400.

20. Dunlap PM, Holmberg JM, Whitney SL (2019) Vestibular rehabilitation: advances in peripheral and central vestibular disorders. Curr Opin Neurol 32(1): 137-144

21. Kouris I, Sarafidis M, Androutsou T, Koutsouris D (2018) HOLOBALANCE An Augmented Reality virtual trainer solution forbalance training and fall prevention. Conf Proc IEEE Eng Med Biol Soc 2018: 4233-4236.

22. Alves CC, Silva ALS (2019) Pediatric Vestibular Rehabilitation: A Case Study. Pediatr Phys Ther 31(4): E14-E19.

23. Proffitt R, Lange B (2015) Feasibility of a customized, in-home, gamebased stroke exercise program using the Microsoft Kinect ${ }^{\circledR}$ Sensor International Journal of Telerehabilitation 7(2): 23-34 


\section{ISSN: 2574-1241}

DOI: 10.26717/BJSTR.2019.22.003740

Lilian Felipe. Biomed J Sci \& Tech Res

(c) (i) This work is licensed under Creative

Submission Link: https://biomedres.us/submit-manuscript.php

$\begin{array}{ll}\text { BIOMEDICAL } & \text { Assets of Publishing with us } \\ \text { RESEARCHES } & \text { Global archiving of articles } \\ & \text { - Immediate, unrestricted online access } \\ & \text { - Rigorous Peer Review Process } \\ \end{array}$

